\title{
Hispanismes
}

Revue de la Société des Hispanistes Français

16 | 2020

Langues en contact avec l'espagnol et défis sociétaux

\section{Convivencia social y desafíos lingüísticos en Ceuta y Melilla}

Cohabitation sociale et défis linguistiques à Ceuta et Melilla

Social cohabitation and language challenges in Ceuta and Melilla

\section{Alicia Fernández García}

\section{(2) OpenEdition}

\section{Journals}

\section{Edición electrónica}

URL: https://journals.openedition.org/hispanismes/748

DOI: 10.4000/hispanismes.748

ISSN: 2270-0765

Editor

Société des Hispanistes Français

\section{Referencia electrónica}

Alicia Fernández García, «Convivencia social y desafíos lingüísticos en Ceuta y Melilla», HispanismeS [En línea], 16 | 2020, Publicado el 01 diciembre 2020, consultado el 31 agosto 2021. URL: http:// journals.openedition.org/hispanismes/748 ; DOI: https://doi.org/10.4000/hispanismes.748

Este documento fue generado automáticamente el 31 agosto 2021.

es contenus de cette revue sont mis à disposition selon les termes de la Licence Creative Commons Attribution - Pas d'Utilisation Commerciale - Pas de Modification 4.0 International. 


\title{
Convivencia social y desafíos lingüísticos en Ceuta y Melilla
}

\author{
Cohabitation sociale et défis linguistiques à Ceuta et Melilla \\ Social cohabitation and language challenges in Ceuta and Melilla
}

Alicia Fernández García

\section{Introducción}

1 Olvidados con frecuencia debido en parte por su lejanía, desconocidos incluso hasta el día de hoy pese a su riqueza cultural y singularidad sociolingüística, relegados a menudo al simple papel de ciudades-fronteras desbordadas por la presión migratoria y por todo tipo de tráfico, los enclaves de Ceuta y Melilla conocen desde hace algunos años la emergencia de una nueva consciencia plurilingüe. Así, la enseñanza del dariya y del tamazight ${ }^{1}$, dos lenguas habladas en Ceuta y en Melilla respectivamente por los españoles de origen marroquí y los marroquíes que viven en ambas ciudades, ha sido promovida gracias a algunas iniciativas particulares: en Ceuta, por ejemplo, la Casa de la juventud ha incluido en su agenda de cultura cursos de dariya ${ }^{2}$. En el caso del tamazight, destacaré que en algunas ocasiones su enseñanza se ha impartido en el seno de las fuerzas armadas y también se ha propuesto a los funcionarios locales ${ }^{3}$.

Dichas iniciativas lingüísticas han sido tratadas a menudo con cierta carga satírica como lo ha demostrado alguna que otra viñeta publicada en la prensa local ${ }^{4}$, o rechazadas cuando su objetivo es promover el bilingüismo de los escolares de ambas ciudades $^{5}$. Actitudes que revelan cómo la realidad plurilingüe de Ceuta y Melilla sigue sin tomarse en serio relegando al dariya y el tamazight a un papel secundario y al espacio de lo informal. A este respecto es importante subrayar que si la enseñanza informal de estas dos lenguas o dialectos, según el especialista que las estudie, ha sido saludada por las autoridades locales, en estas dos ciudades se reitera constantemente la necesidad de no confundir las prácticas interculturales y los intercambios lingüísticos 
con lo «políticamente correcto», es decir, la necesidad de preservar una sola lengua oficial tanto en las aulas como en el espacio público e instituciones de estas ciudades.

3 A partir de estas consideraciones dispares con las que se promueve el conocimiento del dariya y del tamazight, pero no su reconocimiento, esta contribución estudiará los desafíos sociales e identitarios generados en estas dos zonas de contacto que son los enclaves españoles de Ceuta y Melilla. Para ello, estructuraré el presente artículo en dos partes. En primer lugar, presentaré la realidad sociodemográfica de las dos principales comunidades que viven en ambos territorios aludiendo a algunos datos, pero interesándome sobre todo en los desafíos que representa la convivencia sociocultural y en el impacto que tiene en la construcción identitaria.

Después abordaré, en una segunda parte, la cuestión del nacionalismo lingüístico. Por nacionalismo lingüístico entiendo la voluntad por mantener la dominación del castellano sobre el resto de prácticas y representaciones lingüísticas. En la España actual, la oposición entre los llamados nacionalistas y no nacionalistas ha alimentado el debate público e incluso se ha convertido en un desafío mayor que pone en tela de juicio el propio modelo territorial ${ }^{7}$. En medio de este debate, las reivindicaciones acerca de las lenguas minoritarias se perciben a menudo como problemáticas, presentándose bajo el signo de la amenaza y pocas veces a través del prisma de una riqueza colectiva que habría que defender. A partir de esta idea, propongo una reflexión introductora sobre las características del nacionalismo español en Ceuta y Melilla, el cual se basa en la idea de que el castellano constituye la lengua común ${ }^{8}$ del estado español.

De esta manera, ¿cuál es la naturaleza de la convivencia en Ceuta y Melilla y cuál es su impacto en la construcción identitaria en el seno de estos dos mosaicos socioculturales? ¿Cómo son percibidas las diferentes lenguas habladas en estos enclaves plurilingües y cuál son las resonancias del nacionalismo lingüístico español? Estas dos problemáticas constituirán los ejes de lectura de la presente contribución. Los datos y resultados utilizados en la misma, así como las citas movilizadas están tomadas de los numerosos trabajos de campo realizados en el marco de mi tesis doctoral ${ }^{9}$.

\section{Ceuta y Melilla bajo el prisma de la convivencia}

\subsection{La comunidad cristiana: el grupo mayoritario y dominante}

6 Aunque no cabe la menor duda que existen laicos entre los habitantes de Ceuta y Melilla, mis estancias en ambas ciudades me han permitido constatar que la religión se impone en estos dos enclaves como el principal rasgo determinante de la pertenencia social. En lo que respecta a la comunidad cristiana, diré que el grado de religiosidad y la práctica del catolicismo son fuertes, incluso omnipresentes, en el seno de este grupo social mayoritario. En la actualidad, Ceuta y Melilla disponen de un número considerable de iglesias y de capillas salpicadas en todo el espacio urbano, y pese a sus perímetros reducidos (ni siquiera $18 \mathrm{~km}^{2}$ ), también cuentan con la presencia de diferentes órdenes religiosas e incluso de un grupo del Opus Dei.

7 En el caso de Ceuta, la religiosidad no es solo competencia del personal religioso ni tampoco un legado arquitectónico, sino que se presenta como una práctica social llena de vitalidad y en pleno auge. Es la impresión que he tenido cuando delante de los numerosos lugares de culto (iglesias, retratos y bustos de vírgenes o de cristos, cruces, etc.), numerosos habitantes se arrodillan para hacer la genuflexión y/o para rezar. Una 
religiosidad que se vive intensamente todos los jueves cuando los cristianos se juntan cada uno en su cofradía respectiva para ensayar las marchas que animarán las procesiones de Semana Santa. La religiosidad en Ceuta es también una fe que lleva a un gran número de habitantes a asistir cada domingo a misa para escuchar la palabra de Dios, llenando de manera espectacular las iglesias ceutíes. Y es que los domingos en Ceuta son días de una religiosidad bastante ritualizada, ya que a la imperdonable misa dominical le sigue el encuentro convival y festivo entre amigos y/ o en familia en algunas de las maravillosas terrazas bañadas por el sol y la brisa del mediterráneo ${ }^{10}$.

Además, mis entrevistas con algunos párrocos de estas ciudades me han confirmado que el porcentaje de vocaciones religiosas en estos dos enclaves es bastante elevado si lo comparamos con el de la Península. Por último, aludiré a otra expresión popular del fervor religioso local como es la celebración de las fiestas patronales en honor a la virgen de África en Ceuta o a la virgen de la Victoria en Melilla cuya inauguración se hace de la mano de una misa presidida por las autoridades políticas y militares. Vírgenes dotadas de un importante capital simbólico por haber cumplido una misión comparable a la de Santiago, patrón de España y popularmente conocido como «mata moros».

\subsection{La comunidad musulmana: crecimiento demográfico e integración progresiva}

9 La presencia de la comunidad musulmana de Ceuta y de Melilla es secular y representa hoy más del $40 \%$ del conjunto de la población ${ }^{11}$. Prueba de este anclaje histórico es que Ceuta cuenta con 33 mezquitas mientras que en Melilla existen 14. Desde un punto de vista demográfico, la población musulmana de ambas ciudades se divide en tres grandes grupos: 1) aquellos musulmanes cuyo arraigo es secular, 2) aquellos de instalación reciente y, por último, 3) los musulmanes considerados como población flotante, cuyo número es muy difícil de estimar ya que está constituido por personas que llevan una vida transfronteriza, es decir, a caballo entre estas dos ciudades y el vecino Marruecos. Hay que señalar que más de 25.000 marroquíes atraviesan cotidianamente el paso fronterizo que separa estos dos territorios españoles de Marruecos ${ }^{12}$. Una frontera muy permeable pese a las sucesivas tentativas por blindarla, un verdadero «colador», como lo escucho a menudo en la boca de sus habitantes, que ha provocado focos de clandestinidad, así como el hacinamiento de numerosos marroquíes en situación irregular en los barrios cercanos a la frontera. La comunidad musulmana de Ceuta y Melilla es sin duda alguna una de las más importantes en España, pero también es la más desconocida de la sociedad española, no solo por la imposibilidad y dificultades del recuento, sino también por la indiferencia y pasividad de las autoridades ${ }^{13}$.

La religiosidad musulmana en Ceuta y en Melilla se forja alrededor de un conglomerado de comunidades religiosas, lugares de culto y asociaciones socioculturales que reflejan la heterogeneidad de los miembros de este colectivo ${ }^{14}$. Más allá del interés sociodemográfico por la comunidad musulmana y de la difícil tarea de abordar e intentar comprender el poder de las representaciones que genera y la diversidad de los individuos que la componen, el estudio de los musulmanes de Ceuta y de Melilla no puede hacerse sin tener presente su lucha social por la obtención de la nacionalidad española en el contexto de la Ley de extranjería de $1985^{15}$ y por el reconocimiento en el seno de las sociedades ceutíes y melillenses de su pertenencia e identidad nacional. A 
este respecto aludiré a las consideraciones de algunos especialistas para quienes, tras las naturalizaciones acordadas tras la entrada en vigor de la Ley de extranjería de 1985, el colectivo musulmán de ambas ciudades atraviesa uno de los procesos de cambio más intensos de la historia de las ciudades ${ }^{16}$.

\subsection{Los desafíos de la convivencia y los dilemas de la identidad en Ceuta y Melilla}

11 Cabe preguntarse ahora cómo se organiza el vivir juntos, la convivencia sociocultural en los enclaves de Ceuta y de Melilla. En estas dos ciudades, la población se reparte en diferentes distritos y se distribuye principalmente en función de sus orígenes, lo que muestra un reparto comunitario de la población ${ }^{17}$. Además, si se tiene en cuenta la ubicación geográfica de los diferentes barrios, es de notar la existencia de un clivaje nítido entre el centro y la periferia. Esta segregación social del espacio urbano me lleva a formular la siguiente hipótesis sintetizada en una frase: «una ciudad, dos espacios». Por consiguiente, el tejido urbano de los enclaves de Ceuta y de Melilla pone de realce una estratificación sociodemográfica. En estas dos ciudades, el reparto urbano de la población muestra una tendencia bastante clara a la segregación espacial y social que las políticas públicas locales no han sido capaces o simplemente no han querido refrenar. A este respecto, subrayaré que a día de hoy no existe ninguna iniciativa pública ni tampoco ninguna política urbana para tratar de invertir la tendencia y conseguir una sociedad más mixta ${ }^{18}$.

Si esta segregación urbana no constituye un fenómeno innovador, único o exclusivo de dichas ciudades enclavadas, lo que sí resulta original es la paradoja entre la existencia de una división social del espacio, reveladora de lo que Henri Lefèbvre consideraba la proyección en el suelo de las desigualdades sociales ${ }^{19}$, y los discursos oficiales que celebran la existencia de una convivencia idílica entre las diferentes culturas. Tal desfase entre la realidad de una ciudad segregada y las alusiones a una armoniosa y placentera convivencia por parte de las autoridades, me lleva a interesarme por los vínculos existentes entre desigualdad urbana e identidad, y más precisamente, por cómo se forjan las identidades en estos dos mosaicos socioculturales en tensión que son las ciudades de Ceuta y de Melilla. Identidades que se construyen a partir de referentes múltiples, tres en particular: el referente religioso, el referente patriótico y el referente local, que también podemos llamar la autoctonía ${ }^{20}$. Y estas lógicas identitarias parecen ser comunes al conjunto de la población, es decir, tanto para los españoles de origen peninsular como para aquellos de origen marroquí.

13 Así, en Ceuta y Melilla, nos encontramos con identidades impregnadas de un referencial religioso, ya que la religión continúa siendo el centro neurálgico de la pertenencia, así como el rasgo estigmático de la identidad. Para numerosos habitantes, la religión es la culpable del fracaso de la integración en estas ciudades y es que, en estos enclaves, la religión católica o musulmana estructura la vida social y llega incluso a superar la esfera privada para adueñarse de la de toda la comunidad. A modo de testimonio, citaré el ejemplo de las autoridades locales que a menudo recurren a la legitimidad de líderes religiosos y no a la de los actores sociales o políticos para resolver problemas o atenuar las tensiones entre las dos comunidades. Con respecto a los habitantes de origen marroquí, el hecho de definirse como musulmanes de Ceuta y de Melilla constituye un referencial religioso interpretado por ciertos habitantes de origen peninsular como 
sintomático de la bipolarización de su identidad y de la incompatibilidad de ser musulmán y español. Esta identidad múltiple de los españoles de origen marroquí es rechazada e incluso percibida como una neurosis identitaria, así como la razón que impide a los musulmanes de ambas ciudades experimentar un verdadero sentimiento patriótico. Tales consideraciones olvidan que jamás la consciencia identitaria se ha opuesto al sentimiento patriótico.

En estos dos enclaves, el patriotismo constituye el sentimiento más vehiculado por los habitantes a la hora de definir su pertenencia. Así, en mis numerosos trabajos de campo, he constatado su entrega y devoción por la patria España, un término bastante connotado en la península pero que en Ceuta y Melilla aún posee gran valor: «Yo me siento ceutí claro está, pero me siento ante todo y sobre todo español y poseo un gran sentimiento patriótico» ${ }^{21}$, e incluso "yo soy de Melilla, España es mi patria, mi nación, viva España y viva el rey» ${ }^{22}$. Este fervor patriótico también queda plasmado en el testimonio de otro encuestado que me confiesa su inmensa decepción al realizar el servicio militar, la mili, en la península donde descubrió la escasa fibra patriótica de los peninsulares ${ }^{23}$.

En mis entrevistas con los españoles de origen marroquí, la afirmación «reivindicar la españolidad» o el carácter español, se ha convertido en un leitmotiv debido a la desconfianza que suelen suscitar para buena parte de los españoles de origen peninsular: «Somos de aquí (Ceuta y Melilla), pero lo tenemos que justificar siempre ya que a menudo no se nos cree» ${ }^{24}$. El miedo e incluso se podría decir el fantasma de una conspiración promarroquí por parte de estos musulmanes españoles parece ser la razón de dicha desconfianza. Una conspiración insensata si tenemos en cuenta que la mayoría de mis encuestados que se declaran musulmanes afirman lo siguiente: «Aquí encontrarás muy poquitos musulmanes que se sientan marroquís». Una certeza que parece ser consensual entre los miembros de este colectivo.

16 A pesar de estos discursos, el patriotismo de los musulmanes posee un carácter asimétrico ya que, si para algunos poseer el DNI español constituye un éxito simbolizado con la imagen metafórica del «cojín de los musulmanes», ya que aporta seguridad, por otro lado, la marginalidad social de este colectivo engendra un cierto malestar identitario. Esto es lo que se puede extraer del discurso «victimista» de ciertos jóvenes musulmanes que se sienten excluidos de la sociedad de Ceuta simplemente por ser «moros», recuperando así el viejo antagonismo histórico. La pertenencia aparece entonces como un estigma social que condiciona la posición del individuo en la sociedad de ambas ciudades. Españoles de origen marroquí de quienes se sospecha y a quienes se les acusa de tener un comportamiento camaleónico: «Son unos chaqueteros» escucho sobre ellos con frecuencia en estas ciudades. Finalmente, si para ciertos españoles de origen marroquí la identidad es la expresión de un patriotismo parecido al expresado por aquellos de origen peninsular y sintetizado con la fórmula: «español y orgulloso de serlo», otros declaran tener una identidad múltiple expresada de la siguiente manera: «aquí el DNI español y en Marruecos, el pasaporte marroquí».

17 En Ceuta y Melilla, la legitimidad del suelo y la autoctonía se convierten en una verdadera herramienta de exclusión que se apoya en el principio de «anterioridad histórica» y que se expresa con la sentencia: «yo estaba aquí antes». Así, el lugar de nacimiento constituye un clivaje persistente entre los viejos y los nuevos habitantes. Si un cierto pudor se observa en las declaraciones de los españoles de origen marroquí entrevistados que les «impide» emitir abiertamente críticas dañinas con respecto a los 
otros habitantes, este reparo o simple pudor desaparece cuando se trata de hablar de los vecinos marroquíes recientemente instalados en los enclaves. Las lenguas se embalan para tratarles de «turcos» y de «catetillos». Por último, añadiré que este clivaje entre nuevos y viejos habitantes también se da en el seno de la comunidad de origen peninsular. En Melilla, se distingue a los «melilleros», es decir, a los recién llegados, de los «melillenses», término utilizado para referirse a los autóctonos y peninsulares de pura cepa. En Ceuta, la distinción se hace entre el "caballa», entendamos con este término el autóctono, y el que acaba de llegar. El lugar de nacimiento legitima por consiguiente el arraigo local y se impone como un factor determinante en la construcción identitaria de los habitantes de Ceuta y de Melilla.

\section{Nacionalismo lingüístico en Ceuta y en Melilla}

En esta segunda parte pretendo estudiar las ciudades de Ceuta y de Melilla como «laboratorios» del plurilingüismo, debido a la presencia y al contacto de varias lenguas. Si el castellano es la lengua oficial de estos enclaves, los españoles de origen marroquí, así como los marroquíes que en ellas viven, tienen como lengua materna el dariya o árabe dialectal en Ceuta y el tamazight en Melilla. Estas dos lenguas son por consiguiente habladas por casi el $40 \%$ de sus poblaciones respectivas, un porcentaje que es superior por ejemplo al de vascohablantes en el País Vasco. A diferencia de otras regiones españolas bilingües, en estas dos ciudades raras veces ha habido reivindicación o defensa de dichas lenguas, lo máximo que se ha conseguido ha sido un reconocimiento de la pluralidad cultural de sus habitantes.

\subsection{Las justificaciones normativas y políticas del nacionalismo lingüístico}

Desde el año 2004, en los enclaves de Ceuta y Melilla ha emergido una nueva consciencia plurilingüe y desde hace algunos años, el aprendizaje del dariya y del tamazight ha estado animado por iniciativas particulares: en Ceuta, la Casa de la juventud promueve cursos de dariya. En Melilla, el aprendizaje del tamazight se ha introducido algunas veces en los rangos del ejército ${ }^{25} \mathrm{y}$ durante algunos años se han propuesto a los funcionarios locales cursos de iniciación ${ }^{26}$. De igual modo, el Instituto de las Culturas cuyos presidentes son elegidos entre los miembros del equipo municipal, creó en 2015 los llamados «Los jueves amazighs» con la finalidad de «dar difusión a la cultura amazigh y acercarla a los ciudadanos $»^{27}$. Un aprendizaje informal e intermitente que las autoridades locales aplauden sin dejar de afirmar la necesidad de no confundir las prácticas interculturales y los intercambios lingüísticos con lo "políticamente correcto», entiéndase con ello la necesidad de preservar una única lengua oficial, tanto en las aulas como en las instituciones de ambas ciudades. Así, mientras que en el seno de las comunidades autónomas consideradas como «nacionalidades históricas», el uso y la enseñanza de las lenguas suscita debate, pero existe en la práctica, la cuestión parece seguir siendo tabú en Ceuta y Melilla.

En estas ciudades, las tímidas reivindicaciones lingüísticas y culturales del colectivo musulmán provocan el rechazo e incluso el recelo de ciertos habitantes al ser a menudo concebidas como antinómicas a la identidad colectiva y nacional. En estos dos enclaves españoles, el castellano desempeña un papel simbólico en cuanto elemento 
representativo de la pertenencia a un grupo mayoritario, mientras que las otras lenguas, el tamazight en Melilla y el dariya en Ceuta, se ven excluidas del proyecto nacionalista e incluso son presentadas como perjudiciales para la cohesión nacional, aunque sean entendidas y ampliamente utilizadas por buena parte de sus habitantes. Este conflicto lingüístico y simbólico revela el alcance del prestigio social de las lenguas, que se manifiesta con la creencia en la existencia de un grupo considerado como el grupo de referencia, y el reconocimiento de su poder social ${ }^{28}$. Un prestigio que no depende de criterios lingüísticos sino más bien políticos ${ }^{29}$. Por consiguiente, consideradas como dos lenguas sin prestigio, el dariya y el tamazight se ven desacreditados e infravalorados, así como sus locutores.

Otra justificación del nacionalismo lingüístico español es el hecho de considerar el castellano como la lengua común y la única capaz de garantizar la comunicación entre todos los ciudadanos provocando así la exclusión de las otras lenguas. El pensamiento nacionalista lingüístico español se apoya en la exaltación del concepto de «lengua común» y en el desprestigio del de «lengua propia». En estos enclaves, la legitimación histórica del castellano como «lengua común» se apoya en el recurso a un discurso con fuerte carácter nacionalista que opone el autóctono al extranjero. De este modo, algunos habitantes consideran el dariya y el tamazight como dos «lenguas extranjeras» a las ciudades: «Vamos a ver, a un español cuando va a Noruega qué le pasa, pues que si no aprende la lengua del país a los dos meses le echan, pues aquí igual, que hay muchos que no saben hablar español, y eso no puede ser» ${ }^{30}$. En este sentido, el presidente de Melilla, Juan José Imbroda, calificó el tamazight como una «lengua no española» ${ }^{31}$. Por su parte, en 2010, el representante del gobierno en Ceuta consideró el dariya como un «dialecto extranjero»: «La presencia de tal dialecto no es tradicional, sino fruto de una relativamente reciente y muy numerosa afluencia de personas de otro país» ${ }^{32}$.

Para el nacionalismo lingüístico español ${ }^{33}$, la propia situación lingüística de Ceuta y Melilla, con la presencia de varias lenguas en contacto, se concibe como un factor de desorden lingüístico que genera «un mal árabe y un mal español». En efecto, numerosos entrevistados de origen peninsular reprochan a los musulmanes de estas ciudades el hablar un castellano aproximativo. Este también parece ser el discurso oficial de las autoridades que recalcan constantemente la necesidad de reforzar el aprendizaje del castellano, refiriéndose muy a menudo a su desconocimiento por parte de ciertos sectores de la población. Estos propósitos vehiculan la presencia de un fuerte «monolingüismo militante» que se concretiza en la «certeza» de que los bilingües castellanos/dariya de Ceuta y castellano/tamazight de Melilla emplean lenguas minoritarias y sin ninguna utilidad ${ }^{34}$.

Otra manifestación de ese monolingüismo militante es el empeño en catalogar el dariya y el tamazight como simples dialectos ${ }^{35} \mathrm{y}$ resulta interesante focalizarlos en esta tentativa de categorización para nada inocente que pasa por alto que la gran diferencia entre lengua y dialecto es el grado de reconocimiento oficial de su estatuto por parte del Estado o de las autoridades. De este modo, catalogar de dialectos al dariya y al tamazight y de lengua al castellano permite consolidar la dominación social de este último, que por ser «lengua» se considera superior y con más prestigio social. Además, la ausencia de codificación o la codificación en curso del dariya y del tamazight, lo que las vuelve muy sensibles a los préstamos lingüísticos, sirve a ciertos especialistas para considerarlas como un «hablar» o como una variedad oral. A través de estas reflexiones tan apasionadas podemos calibrar la batalla por el prestigio social de las lenguas en la 
que se olvida lo esencial que es que «una lengua es un dialecto que ha conseguido imponerse a los otros» ${ }^{36}$.

Una última manifestación del monolingüismo militante en estas dos ciudades es el borrado, por no decir la negación, de estas lenguas del espacio urbano. Diré a este respecto que en las calles de Ceuta y de Melilla, no hay carteles en tamazight ni en dariya, ni tan siquiera en la frontera con Marruecos por donde transitan cada día numerosos locutores de estas dos lenguas. En las escuelas de ambas ciudades, ningún espacio se les ha reservado. Este destierro lingüístico voluntario del dariya y del tamazight aparece como un dispositivo más de acción del nacionalismo lingüístico español que niega en el espacio urbano el carácter plurilingüe de estas dos ciudades.

\subsection{Efectos múltiples sobre las representaciones lingüísticas}

Se tratará ahora de estudiar las repercusiones de los lugares comunes o de los «axiomas», como lo define Moreno Cabrera $^{37}$, característicos del nacionalismo lingüístico español en las ciudades de Ceuta y de Melilla y promovidos por ciertas personalidades de las ciudades. Se prestará una atención muy particular al impacto que dichos lugares comunes ejercen sobre las representaciones lingüísticas. Para ello me focalizaré en primer lugar en el ámbito escolar, apoyándome en mis intercambios y entrevistas con el personal docente. Aquí, la pluralidad lingüística, si bien es apreciada por el conjunto de los profesores, parece ser con frecuencia la consecuencia de una simple declaración de intenciones. En realidad, durante mis entrevistas, han sido numerosos los profesores que se han mostrado reticentes a introducir en la escuela otra lengua local que no sea el castellano.

Es más, en los establecimientos escolares de las ciudades, existe un cierto clivaje etnolingüístico que revela la fragmentación social del tejido urbano y el comunitarismo de las sociedades ceutí y melillense. Los profesores que he encontrado afirman que existen establecimientos en los que no se entiende ni una sola palabra en castellano, mientras que en otros el dariya o el tamazight están completamente ausentes. Durante mis discusiones, he podido constatar que algunos docentes prohíben el uso del tamazight y del dariya en las aulas y desaconsejan fuertemente a los padres que utilicen estas lenguas con sus hijos. Asimismo, en Ceuta y Melilla, el fracaso escolar de aquellos estudiantes que poseen una lengua materna diferente del castellano se justifica con frecuencia como una consecuencia directa de su bilingüismo, un razonamiento descartado en otras comunidades autónomas bilingües en donde se apunta más bien a una confluencia de múltiples factores. No obstante, esta desregulación lingüísticocultural genera una situación de conflicto representada por la imagen de «la escuela enseña una lengua y el niño piensa en otra lengua» ${ }^{38}$.

Otro efecto del nacionalismo lingüístico español en las representaciones lingüísticas es el empeño de algunas personalidades en considerar toda reivindicación lingüística como prueba de la voluntad de imponer una ciudadanía diferenciada ${ }^{39}$. Una percepción que contrasta con la visión de ciertos investigadores que afirman que el reconocimiento de estas dos lenguas podría convertirse en un importante instrumento de integración ${ }^{40}$. La polémica acerca de las lenguas en las ciudades se reavivó como nunca antes en 2005 durante el debate sobre el estatuto autonómico de las ciudades ${ }^{41}$. La situación del dariya y del tamazight fue objeto de desacuerdos alimentados en parte por la oposición del PP, que acabó aceptando, pese a su inicial rechazo, la protección del dariya en Ceuta y el 
reconocimiento de la pluralidad lingüística de Melilla. Sin embargo, desde que estas dos lenguas son objeto de reivindicaciones, ambas se ven rechazadas en defensa del nacionalismo español. Este fue el caso cuando algunos partidos políticos pidieron que el manejo del dariya en Ceuta se convirtiera en requisito para postular a ciertos puestos públicos. El sindicato UGT denunció lo que consideró una «ofensa para la ciudad». De igual modo, el PP de Ceuta rechazó la proposición de traducir en árabe los carteles de promoción de las Murallas reales, como lo propuso Mohamed Ali, dirigente del partido Caballas que veía en esta iniciativa un atractivo turístico para los visitantes marroquíes ${ }^{42}$. En este mantenimiento de ciertos límites a la pluralidad lingüística de las ciudades hay que interpretar el veto del PP de Ceuta sobre la realización de un estudio científico del dariya ${ }^{43}$.

En Melilla, varios grupos políticos locales como es el caso del partido Coalición por Melilla (CPM), el PSOE y Podemos Melilla e incluso algunos partidos nacionalistas como Esquerra Republicana de Catalunya (ERC) o el Partido Nacionalista Vasco (PNV) han pedido en el transcurso de los últimos años más reconocimiento y visibilidad del tamazight en Melilla ${ }^{44}$. Una de las reivindicaciones políticas más solicitadas ha sido la introducción de la enseñanza del tamazight en las escuelas de la ciudad, petición que fue rechazada por el gobierno central que es quien posee la competencia en educación de la ciudad autónoma, dirigido entonces por el PP y saludada por el alcalde Juan José Imbroda (PP $)^{45}$. El mismo alcalde que ha calificado de insensato y discriminatorio que el conocimiento del tamazight puntúe en algunas oposiciones a la ciudad como lo vienen reivindicado algunos grupos políticos ${ }^{46}$.

29 La propuesta de convivencia lingüística lanzada por ciertos partidos tampoco fue del agrado de Fadela Mohatar (PP), ex-presidenta del Instituto de las Culturas, organismo que se considera sin embargo un ferviente defensor de la cultura y de la lengua tamazight. Su rechazo a la propuesta lanzada en 2013 por ERC pidiendo la cooficialidad del tamazight en Melilla fue contundente, dejando en evidencia la sumisión del Instituto de las Culturas a la línea ideológica del gobierno local ${ }^{47}$. Otro no al tamazight por parte del PP local ha tenido lugar cuando el partido CpM, principal grupo de la oposición, solicitó la presencia de traductores de tamazight en los actos políticos de la ciudad, por ejemplo, durante las ruedas de prensa de los partidos o durante los plenos ${ }^{48}$. $\mathrm{Y}$ es que, para los detractores del nacionalismo lingüístico, el reconocimiento de estas dos lenguas tendría un efecto regresivo sobres las prácticas lingüísticas, lo que no permitiría el progreso social y sumergiría a estas dos ciudades y a sus habitantes en el localismo y en el retroceso cultural.

\section{Conclusiones}

El presente artículo ha intentado llevar a cabo un estudio de Ceuta y Melilla a través de un enfoque intercultural e identitario, pero también lingüístico. A este respecto, una de las primeras conclusiones a las que he llegado es la consideración de ambos territorios como dos espacios de interacción, de circulación y de recomposición de identidades entre las diferentes comunidades culturales (lingüísticas) que aquí conviven. Estas interacciones socioculturales entre los habitantes de origen peninsular y aquellos de origen marroquí me han parecido a la vez intensas y polémicas. El análisis esbozado sobre la distribución socioespacial de la población ceutí y melillense ha confirmado la marcada tendencia a la segregación comunitaria, así como a una duplicación del espacio urbano entre un centro histórico habitado casi exclusivamente por los 
españoles de origen peninsular y una periferia en la que se concentra buena parte de la población de origen marroquí.

En este contexto de repliegue comunitario y de segregación socio urbana, las identidades parecen construirse a partir de tres referentes: la pertenencia religiosa, el patriotismo y la autoctonía o el arraigo. De este modo, la religión me ha parecido estar muy presente en estas ciudades africanas convirtiéndose incluso en rasgo identificador y en marcador de la pertenencia social. De la misma manera, la legitimidad aportada por el lugar de nacimiento se ha convertido en argumento a veces identificador, a veces discriminatorio, para oponer el nativo al forastero. Por último, el patriotismo o más bien el nacionalismo español, término privilegiado en estos enclaves, parece ser un sentimiento común con el que se identifican los habitantes y quizás el único elemento unificador. Sin embargo, los orígenes socioculturales estigmatizan y condicionan el patriotismo de los habitantes y debido a ello, los españoles de origen marroquí son a menudo percibidos como ciudadanos de segunda clase.

En estos dos enclaves españoles en los que conviven diferentes culturas, también he querido interesarme por el papel reconocido a las lenguas en contacto. Como respuesta a este interrogante, el presente artículo ha puesto en evidencia cómo el tamazight, el castellano y el dariya vehiculan una cultura, cierto es, pero también gozan de una imagen colectiva e individual más o menos positiva. Pese a la existencia en cada una de estas ciudades de dos lenguas en contacto (dariya/castellano en Ceuta y tamazight/ castellano en Melilla), la cuestión lingüística en ambas ciudades se conjuga oficialmente en singular siendo así la expresión de un monolingüismo militante sintetizado en el credo: una lengua, una nación. La construcción ideológica del nacionalismo lingüístico en Ceuta y Melilla se caracteriza por la percepción del dariya y del tamazight como una amenaza a la identidad nacional mientras que el castellano se concibe como el elemento central de la "representación de la identidad colectiva» ${ }^{49}$ y el símbolo de la pertenencia al grupo mayoritario.

\section{BIBLIOGRAFÍA}

José Luis ARósteGUI RUIZ, Ceuta a corazón abierto, Ceuta, Ayuntamiento Ceuta, 2002.

María del Carmen AYORA ESTEBAN, «Consideraciones acerca de la relación entre lengua y cultura en el contexto educativo ceutí», Juan Lara Guerreo (ed.), Educación y sociedad. Homenaje al profesor Juan Lara Herrero, Ceuta, Facultad de educación y humanidades de Ceuta, 2009, p. 239-254.

Henri BOYER, Langue et identité. Sur le nationalisme linguistique, Limoges, Lambert-Lucas, 2008.

Henri BOYER, Les langues en conflit, Paris, L'Harmattan, 1991.

Rafael BRIONES, Sol TARRÉS y Oscar SALGUERO, Encuentros. Diversidad religosa en Ceuta y Melilla, Barcelona, Icara, 2013.

Tomás CALVo, Musulmanes y cristianos conviviendo juntos, Ceuta, IEC, 2010. 
Dominique CAUBET, «Arabe maghrébin : passage à l'écrit et institutions», Faits de langues, $\mathrm{n}^{\circ} 13$ (1999), p. 235-244.

Nizha CHATAR MOUMNI, «Vers une standardisation de l'arabe marocain?», Écho des études romanes, vol XI, n 1 (2015), p. 75-92.

Teba ESCRIBANO TORRES, «Análisis cultural y sociodemográfico de la imigración hindú», Actas del II Congreso de Inmigración, interculturalidad y convivencia, Ceuta, 2003, p. 127-136.

Alicia FERNÁNDEZ GARCíA, Vivre ensemble. Conflit et cohabitation à Ceuta et Melilla, Paris, L'Harmattan, 2017.

Alicia FERNÁNDEZ GARCÍA, «La génération de 1986 : l'essor d'une conscience nationale espagnole chez les immigrés marocains à Ceuta et Melilla», Hispanismes [on-line], n 8 (2017), p. 235-255 [consultado el 22/11/2019] <URL: 3_Alicia_FERNANDEZ.pdf (hispanistes.fr) >.

Alicia FERNÁNDEZ GARCÍA, «Ceuta et Melilla, mosaïques socioculturelles : cohabitation sociale et dynamiques identitaires», Yvon Rolland, Jean-Pierre Tardieu, Issa Kanté, Églantine Samouth y Melanie Mezzapesa (eds.), Identités en contextes pluriels, Paris, L'Harmattan, 2017, p. 9-26.

Xavier FERRER GALLARDO, «Acrobacias fronterizas en Ceuta y Melilla. Explorando la gestión de los perímetros terrestres de la Unión Europea en el continente africano», Documents d'anàlisi geogràfica, nº 51 (2008), p.129-149.

Medhi FLORES, «En el nombre de Sebta. La cuestión de la cooficialidad del árabe y otros tabúes», [consultado el 23/02/2020] <URL: http://www.webislam.com/articulos/18178>.

Josua FISHMAN, Sociología del lenguaje, Madrid, Cátedra, 1982 [1968].

Francisco GARCIA MOScoso, «El dialecto árabe de Ceuta a partir de un cuestionario dialectológico», Acta orientalia, vol. 68 (2007), p. 207-246.

María Pilar GONZÁLEZ, «La población musulmana de Ceuta y Melilla», Actas del Congreso Internacional El Estrecho de Gibraltar, UNED-Ayuntamiento de Ceuta, Tomo IV, Madrid, 1998, p. 251-271.

Barbara HERRERO MUÑOZ-COBO, El árabe ceutí: un código mixto reflejo de una identidad mestiza, Ceuta, IEC, 2013.

Rafael JIMÉNEZ GÁLVEZ, «El uso del dialecto árabe marroquí en Ceuta, defensa frente al poder. Un estudio de caso en un centro de secundaria», Actas del I Congreso Árabe Marroquí: estudio, enseñanza y aprendizaje, Cádiz, Servicio de Publicaciones de la Universidad de Cádiz, 2006, p. 129-150.

Henri LEFEBVRE, Le Droit à la ville II : Espace et politique, Paris, Anthropos, 2000 [1973].

Anthony LODGE, Le Français : histoire d'un dialecte devenu langue, Paris, Fayard, 1997.

Catherine MILLER, «Marges et Normes linguistiques au Maroc : un terrain mouvant», Céline Aufauvre, Karine Benafla, Montserrat Emperador et Sihem Najar (eds.), Marges et marginalités au Maroc, Paris, Karthala, 2011, p. 57- 70.

Juan Carlos MORENO CABRERA, «L'évolution du nationalisme linguistique espagnol depuis la transition démocratique (1975-2010)», Alicia Fernandez García et Mathieu Petithomme (eds.), Les nationalismes dans l'Espagne contemporaine (1975-2011). Compétition politique et identités nationales, Paris, Armand Colin, 2012, p. 384-412.

Juan Carlos MORENO CABRERA, «Lengua, nación y nacionalismo español», Henrique Monteagudo Romero (ed.), Linguas, sociedade et política: un debate multidisciplinar, Santiago de Compostela, Consello da cultura Galega, 2012, p.83-123. 
Juan Carlos MORENO CABRERA, «El nacionalismo lingüístico español», Carlos Taibo (ed.), Nacionalismo español. Esencias, memoria e instituciones, Madrid, Catarata, 2007, p. 351-376.

Francisco moscoso GARCíA, «El árabe de Ceuta. Argumentos para su cooficialidad», Francisco Moscoso García, Luis Miguel Pérez Cañada y Paula Santillan Grimm (eds.), Árabe marroquí: de la oralidad a la enseñanza, Cuenca, Universidad de Castilla La Mancha, 2014, p. 95-124.

Isabel PLANET CONTRERAS, Melilla y Ceuta: espacios-frontera hispano-marroquíes, Melilla, Ciudad Autónoma de Ceuta -UNED, 1998.

Carlos rontomé Romero, Ceuta: convivencia y conflicto en una sociedad multiétnica, Ceuta, IEC,2012.

José Manuel RUIZ, «Política lingüística y democracia constitucional», La política lingüística vasca a debate, Vitoria, 2008, p. 9-54.

Carlos RONTOMÉ ROMERo, «Multiculturalidad y ciudadanía diferenciada en Ceuta», Francisco Herrera, José M. Roa, María I. Ramírez, Francisco Mateos y Santiago Ramírez (eds.), Inmigración, interculturalidad y convivencia, Ceuta, IEC, 2003, p. 475-486.

Óscar SALGUERO, «Las comunidades musulmanas de Melilla», Rafael Briones, Sol Tarrés y Óscar Salguero (eds.), Encuentros. Diversidad religosa en Ceuta y Melilla, Barcelona, Icara, 2013, p. 301-348. Sol TARRÉs, «Musulmanes ceutíes», Rafael Briones, Sol Tarrés y Óscar Salguero (eds.), Encuentros. Diversidad religosa en Ceuta y Melilla, Barcelona, Icara, 2013, p. 123-182.

Benjamín TEJERINA MONTAÑA, Nacionalismo y lengua, Madrid, CIS, 1992.

Jesús Tusson, Quinze lliçons sobre el llenguatge (i algunes sortides de to), Badalona, Ara Llibres, 2011.

UCIDE, Estudio demográfico de la población musulmana en España referido a fecha 31/12/2018

[consultado el 2/10/2020] <URL: Estudio demográfico de la población musulmana (ucide.org) >

Ángeles VICENTE, Ceuta: une ville entre deux langues, Paris, L'Harmattan 2005.

\section{Artículos de periódico}

«Por la enseñanza en las escuelas de Melilla del tamazight», Podemos.Melilla [on-line], (consultado el 15/11/2019) [disponible el 13/10/2015] <URL: Por la enseñanza en las escuelas de Melilla del Tamazight - Podemos Melilla>.

«Clausuran el curso de iniciación a la lengua tamazight para los militares», El Faro de Melilla, $31 / 05 / 2017$.

«El gobierno de Melilla rechaza que tenga que haber traductores de bereber», El Faro de Melilla, $31 / 03 / 2017$.

«Los cepemistas proponen el tamazight como lengua vehicular en los colegios», El Faro de Melilla, 04/01/2017.

«El tamazight pide la palabra », El Faro de Melilla, 02/01/2017.

«La Ciudad organiza charlas y talleres para difundir la cultura amazigh», El Faro de Melilla, 07/04/2015.

«¿Tamazight a la fuerza?», El Faro de Melilla, 13/12/2014.

«Los trabajadores transfronterizos: los otros perjudicados por los asaltos», $A B C, 20 / 09 / 2013$. 
«Melilla ve imposible la cooficialidad del tamazigh reclamada por ERC», El Faro de Melilla, $12 / 11 / 2013$.

«Historias de Pepe Caballa y la Pavana», El Faro de Ceuta, 17/10/2013.

«El PP rechaza el tener que hacer un estudio sobre la presencia del dariya», El Faro de Ceuta, $29 / 11 / 2012$.

«El gobierno considera el árabe dialectal una lengua "no tradicional" e "inmigrada" ", Ceuta al día [on-line], (actualizado el 09/12/2010) [consultado el 02/10/2019] <URL: El Gobierno central considera el árabe dialectal de Ceuta una lengua "no tradicional" e "inmigrada" - Educación Ceuta al Día - diario digital de Ceuta (ceutaldia.com)>.

«Dos lenguas autonómicas más», El País, 04/07/2010.

«La enseñanza del tamazight para funcionarios se extiende a Correos», El Faro de Melilla, $02 / 06 / 2010$.

«La administración local pretende normalizar el uso de la lengua tamazight con un curso para empleados públicos», El Faro de Melilla, 22/03/2010.

«Melilla: El PP valora que el Gobierno no haya aprobado que el tamazight se incluya en la enseñanza», Diario Sur, 30/03/2006.

«La presión de nuestro islam», El País, 12/09/2005.

«Imbroda califica de "infumable" pretender que el tamazight sea cooficial en Melilla», Libertad digital [on-line], (actualizado el 08/11/2004) [consultado el 11/10/2019] <URL: Imbroda califica de "infumable" pretender que el tamazight sea cooficial en Melilla - Libertad Digital >.

\section{Entrevistas}

Entrevista con Alfredo, funcionario nacido en Ceuta, realizada el 02/02/2009.

Entrevista con José Manuel, gerente de la pensión La Puntilla de Ceuta, realizada el 27/10/2014.

Entrevista con un miembro de la Hermandad de veteranos de las fuerzas armadas, Ceuta, $27 / 10 / 2014$

Entrevista con Luisa, 42 años, realizada en Melilla el 29/10/2014.

Entrevista con una de las participantes al taller de lectura animado por Verónica Rivera Reyes en un centro escolar del barrio del Príncipe, Ceuta, 30/10/2014.

\section{NOTAS}

1. Tamazight es el término que vamos a utilizar en este artículo ya que es así como esta lengua se nombra a nivel local, pero debemos señalar que dicho término solo se refiere a una de las tres variedades lingüísticas del amazighe: el tachelhite que se habla en el Alto Atlas y en el Anti-Atlas, es decir, en el sur, el tarifite que se habla en la zona del Rif y el tamazight usado en el Medio Atlas, en el centro del país. Sobre la cuestión de la codificación de estas lenguas, $c f$. las siguientes contribuciones: Nizha CHATAR MOUMNI, «Vers une standardisation de l'arabe marocain?», Écho des études romanes, vol XI, $\mathrm{n}^{\circ} 1$ (2015), p. 75-92; Dominique CAUBET, «Arabe maghrébin : passage à l'écrit et institutions», Faits de langues, n 13 (1999), p. 235-244; y el trabajo de Catherine MILLER, «Marges et Normes linguistiques au Maroc : un terrain mouvant», Céline Aufauvre, Karine 
Benafla, Montserrat Emperador y Sihem Najar (eds.), Marges et marginalités au Maroc, Paris, Karthala, 2011, p. 57- 70.

2. Rafael JIMÉNEZ GÁLVEZ, «El uso del dialecto árabe marroquí en Ceuta, defensa frente al poder. Un estudio de caso en un centro de secundaria», Actas del I Congreso Árabe Marroquí: estudio, enseñanza y aprendizaje, Cádiz, Servicio de Publicaciones de la Universidad de Cádiz, 2006, p. 136.

3. «Clausuran el curso de iniciación a la lengua tamazight para los militares», El Faro de Melilla, 31/05/2017; «La administración local pretende normalizar el uso de la lengua tamazight con un curso para empleados públicos», El Faro de Melilla, 22/03/2010.

4. Viñeta de Vicente Álvarez publicada en la serie «Pepe Caballa y la Pavana», El Faro de Ceuta, $17 / 10 / 2003$.

5. «¿Tamazight a la fuerza?», El Faro de Melilla, 13/12/2014.

6. María del Carmen AYORA ESTEBAN, «Consideraciones acerca de la relación entre lengua y cultura en el contexto educativo ceutí», Juan Lara Guerreo (ed.), Educación y sociedad. Homenaje al profesor Juan Lara Herrero, Ceuta, Facultad de educación y humanidades de Ceuta, 2009, p. 239-254

7. Juan Carlos MORENO CABRERA, «El nacionalismo lingüístico español», Carlos Taibo (ed.), Nacionalismo español. Esencias, memoria e instituciones, Madrid, Catarata, 2007, p. 351.

8. Juan Carlos MORENO CABRERA, «L'évolution du nationalisme linguistique espagnol depuis la transition démocratique (1975-2010)», Alicia Fernandez García y Mathieu Petithomme (eds.), Les nationalismes dans l'Espagne contemporaine (1975-2011). Compétition politique et identités nationales, Paris, Armand Colin, 2012, p. 384.

9. Tesis defendida el 27 de septiembre de 2016 en la universidad de Paris Nanterre y realizada bajo la dirección de Mercè Pujol Berché y en cotutela con la universidad de Cádiz (bajo la dirección de Julio Pérez Serrano). Dicha tesis ha obtenido las menciones de Doctorat européen otorgada por la universidad francesa de Paris Nanterre y la de Doctorado internacional de la universidad de Cádiz. También ha recibido el Premio extraordinario de doctorado de la universidad de Cádiz, convocatoria 2016-2017.

10. Con respecto a la diversidad y prácticas religiosas en Ceuta, $c f$. los trabajos siguientes: Rafael BRIONES, Sol TARRÉs y Oscar SALGUERO, Encuentros. Diversidad religosa en Ceuta y Melilla, Barcelona, Icara, 2013; Tomás CALVo, Musulmanes y cristianos conviviendo juntos, IEC, Ceuta, 2010; Teba ESCRIBANO TORRES, "Análisis cultural y sociodemográfico de la imigración hindú», Actas del II Congreso de Inmigración, interculturalidad y convivencia, Ceuta, 2003, p. 127-136; María Pilar GONZÁLEZ, «La población musulmana de Ceuta y Melilla», Actas del Congreso Internacional El Estrecho de Gibraltar, UNED-Ayuntamiento de Ceuta, Tomo IV, Madrid, 1998, p. 251-271; Isabel PLANET CONTRERAS, Melilla y Ceuta: espacios-frontera hispano-marroquies, Melilla, Ciudad Autónoma de CeutaUNED, 1998; Carlos RONTOMÉ ROMERo, Ceuta convivencia y conflicto en una sociedad multiétnica, Ceuta, IEC, 2012; Alicia FERNÁNDEZ GARCÍA, Vivre ensemble. Conflit et cohabitation à Ceuta et Melilla, Paris, L'Harmattan, 2017.

11. A fecha del 1 de enero de 2019, y según un estudio de la UCIDE (Unión de Comunidades Islámicas de España), los musulmanes residentes en Ceuta representaban el $43 \%$ del total. Cf. UCIDE, Estudio demográfico de la población musulmana en España, datos 2018 [consultado el 2/10/2020] <URL: Estudio demográfico de la población musulmana (ucide.org) > .

12. Xavier FERRER GALLARDO, «Acrobacias fronterizas en Ceuta y Melilla. Explorando la gestión de los perímetros terrestres de la Unión Europea en el continente africano», Documents d'anàlisi geogràfica, no 51 (2008), p.137-139. Cf. también el artículo de Rafael PEÑA, «Los trabajadores transfronterizos: los otros perjudicados por los asaltos», $A B C, 20 / 09 / 2013$.

13. $C f$. los estudios demográficos y trabajos estadísticos realizados anualmente por la Unión de comunidades islámicas de España (UCIDE) sobre la población musulmana en España.

14. Sol TARRÉS, «Musulmanes ceutíes», Rafael Briones, Sol Tarrés y Óscar Salguero (eds.), Op. cit., 2013, p. 123-182. 
15. En el contexto de la aprobación de la Ley de Extranjería de 1985 por el gobierno español, la situación de los marroquíes nacidos en las ciudades de Ceuta y Melilla creó una controversia social y política sin precedentes. Estos habitantes invisibles jurídicamente, se apropiaron por primera vez de un espacio público hasta entonces reservado a la comunidad de españoles de origen peninsular. Cf. Alicia FERNÁNDEZ GARCÍA, «La génération de 1986 : l'essor d'une conscience nationale espagnole chez les immigrés marocains à Ceuta et Melilla», Hispanismes [on-line], $\mathrm{n}^{\circ} 8$ (2017), p. 235-255 [consultado el 22/11/2019], <URL: 3_Alicia_FERNANDEZ.pdf (hispanistes.fr) >.

16. Óscar SALGUERO, «Las comunidades musulmanas de Melilla», Rafael Briones, Sol Tarrés y Óscar Salguero (eds.), op. cit., 2013, p. 309.

17. Alicia FERNÁNDEZ GARCíA, op. cit., 2017, p. 186-193.

18. Sobre este punto, es de notar que, en algunos países, por ejemplo, en Francia, el fenómeno de la segregación ocupa desde hace más de veinte años un lugar central en el debate público y numerosas políticas públicas se han llevado a cabo, cierto es, con más o menos éxito. Una de las medidas más emblemáticas de las políticas urbanas aprobadas con el objetivo de lograr una sociedad más mixta ha sido la adopción en 2000 de la ley Solidarité et Renouvellement urbain que obliga a las localidades y municipios a disponer de al menos un $20 \%$ de viviendas de alquiler social.

19. Henri LEFEBVRE, Le Droit à la ville II : Espace et politique, Paris, Anthropos, 2000 [1973], p. 141-160.

20. Alicia FERNÁNDEZ GARCíA, «Ceuta et Melilla, mosaïques socioculturelles : cohabitation sociale et dynamiques identitaires», Yvon Rolland, Jean-Pierre Tardieu, Issa Kanté, Églantine Samouth y Melanie Mezzapesa (eds.), Identités en contextes pluriels, Paris, L'Harmattan, 2017, p. 9-26.

21. Entrevista con Alfredo, funcionario nacido en Ceuta, realizada el 02/02/2009.

22. Entrevista con Luisa, 42 años, realizada en Melilla el 29/10/2014.

23. Entrevista con José Manuel, gerente de la pensión La Puntilla de Ceuta, realizada el $27 / 10 / 2014$.

24. Entrevista con una de las participantes al taller de lectura animado por Verónica Rivera Reyes en un centro escolar del barrio del Príncipe, Ceuta, 30/10/2014.

25. El Faro de Melilla, 22/03/2010.

26. «La enseñanza del tamazight para funcionarios se extiende a Correos», El Faro de Melilla, 02/06/2010.

27. «La Ciudad organiza charlas y talleres para difundir la cultura amazigh», El Faro de Melilla, 07/04/2015.

28. Henri BOYER, Langue et identité. Sur le nationalisme linguistique, Limoges, Lambert-Lucas, 2008, p.

71. Leer también del mismo autor, Les langues en conflit, Paris, L'Harmattan, 1991.

29. Josua FISHMAN, Sociología del lenguaje, Madrid, Cátedra, 1982 [1968], p. 74-76.

30. Entrevista con un miembro de la Hermandad de veteranos de las fuerzas armadas, Ceuta, $27 / 10 / 2014$.

31. «Imbroda califica de "infumable" pretender que el tamazight sea cooficial en Melilla», Libertad digital [on-line], (actualizado el 08/11/2004) [consultado el 11/10/2019] <URL: Imbroda califica de "infumable" pretender que el tamazight sea cooficial en Melilla - Libertad Digital >.

32. «El gobierno considera el árabe dialectal una lengua "no tradicional" e "inmigrada"», Ceuta al día [on-line], (actualizado el 09 /12/2010) [consultado el 02/10/2019], <URL: El Gobierno central considera el árabe dialectal de Ceuta una lengua "no tradicional" e "inmigrada" - Educación Ceuta al Día - diario digital de Ceuta (ceutaldia.com)>.

33. José Manuel RUIZ, «Política lingüística y democracia constitucional», La política lingüística vasca a debate, Vitoria, 2008, p. 9-54.

34. Jesús TUSSon, Quinze lliçons sobre el llenguatge (i algunes sortides de to), Badalona, Ara Llibres, 2011, p. 19. 
35. Barbara HERRERO MUÑOZ-COBO, El árabe ceutí: un código mixto reflejo de una identidad mestiza, Ceuta, IEC, 2013, p. 24; Francisco GARCIA MOSCOSo, «El dialecto árabe de Ceuta a partir de un cuestionario dialectológico», Acta orientalia, vol. 68, (2007), p. 207-209; Ángeles VICENTE, Ceuta: une ville entre deux langues, Paris, L'Harmattan 2005, p. 61-67.

36. Anthony LODGE, Le Français : histoire d'un dialecte devenu langue, Paris, Fayard, 1997.

37. Juan Carlos MORENO CABRERA, «Lengua, nación y nacionalismo español», Henrique Monteagudo Romero (ed.), Linguas, sociedade et política: un debate multidisciplinar, Santiago de Compostela, Consello da cultura Galega, 2012, p. 83-123.

38. José Luis arósstegui ruiz, Ceuta a corazón abierto, Ceuta, Ayuntamiento Ceuta, 2002, p. 102.

39. Carlos RONTOMÉ ROMERo, «Multiculturalidad y ciudadanía diferenciada en Ceuta», Francisco Herrera, José M. Roa, María I. Ramírez, Francisco Mateos y Santiago Ramírez (eds.), Inmigración, interculturalidad y convivencia, Ceuta, IEC, 2003, p. 479.

40. Medhi FLORES, «En el nombre de Sebta. La cuestión de la cooficialidad del árabe y otros tabúes», [consultado el 23/02/2020] <URL: http://www.webislam.com/articulos/18178>; Francisco moscoso GARCíA, «El árabe de Ceuta. Argumentos para su cooficialidad», Francisco Moscoso García, Luis Miguel Pérez Cañada y Paula Santillan Grimm (eds.), Árabe marroquí: de la oralidad a la enseñanza, Cuenca, Universidad de Castilla La Mancha, 2014, p. 95-124.

41. Rafael JIMÉNEZ GÁLVEZ, «El uso del dialecto árabe marroquí en Ceuta, defensa frente al poder. Un estudio de caso en un centro de secundaria», Actas del primer Congreso Árabe Marroquí: estudio, enseñanza y aprendizaje, Cádiz, Servicio de Publicaciones de la Universidad de Cádiz, (2006), p. 129-150.

42. El País,12/09/2005.

43. El Faro de Ceuta, 29/11/2012.

44. «El tamazight pide la palabra », El Faro de Melilla, 02/01/2017; «Por la enseñanza en las escuelas de Melilla del tamazight», Podemos.Melilla [on-line], (consultado el 15/11/2019) [disponible el 13/10/2015], <URL: Por la enseñanza en las escuelas de Melilla del Tamazight Podemos Melilla>; «Los cepemistas proponen el tamazight como lengua vehicular en los colegios», El Faro de Melilla, 04/01/2017.

45. «Melilla: El PP valora que el Gobierno no haya aprobado que el tamazight se incluya en la enseñanza», Diario Sur, 30/03/2006.

46. «Dos lenguas autonómicas más», El País, 04/07/2010.

47. «Melilla ve imposible la cooficialidad del tamazight reclamada por ERC», El Faro de Melilla, $12 / 11 / 2013$

48. «El gobierno de Melilla rechaza que tenga que haber traductores de bereber», El Faro de Melilla, 31/03/2017.

49. Benjamín TEJERINA MONTAÑA, Nacionalismo y lengua, Madrid, CIS, 1992, p. 52-72.

\section{RESÚMENES}

Cette contribution étudie les villes espagnoles de Ceuta et Melilla. Plus particulièrement, elle s'intéresse à la nature de la cohabitation sociale, à son impact sur les identités des habitants et aux modes d'identification dans les sociétés de ces villes. De même, le regard sera porté sur les défis sociétaux que doivent affronter les communautés habitant ces enclaves où existe une importante pratique bilingue. 
This contribution studies the Spanish cities of Ceuta and Melilla, and in particular, looks at the nature of their social coexistence, its impact on the cultural identities of their inhabitants, as well as the modes of identification in the societies of these cities. Similarly, the focus will be on the societal challenges faced by the communities living in these enclaves, where there is an important bilingual practice.

\section{ÍNDICE}

Mots-clés: Ceuta, Melilla, nationalisme linguistique, cohabitation sociale, identité, ségrégation Keywords: Ceuta, linguistic nationalism, Melilla, social coexistence, identity, segregation

\section{AUTOR}

\section{ALICIA FERNÁNDEZ GARCÍA}

Université Paris $8 \cdot$ Vincennes $\cdot$ Saint-Denis 